\title{
Erratum to: Endogenous CCL2 neutralization restricts HIV-1 replication in primary human mac- rophages by inhibiting viral DNA accumulation
}

Michela Sabbatucci', Daniela Angela Covino ${ }^{1}$, Cristina Purificato ${ }^{1}$, Alessandra Mallano ${ }^{2}$, Maurizio Federico ${ }^{3}$, Jing Lu', Arturo Ottavio Rinaldi4 ${ }^{4}$, Matteo Pellegrini ${ }^{4}$, Roberta Bona ${ }^{2}$, Zuleika Michelini ${ }^{2}$, Andrea Cara ${ }^{2}$, Stefano Vella ${ }^{2}$, Sandra Gessani ${ }^{1}$, Mauro Andreotti ${ }^{2}$ and Laura Fantuzzi ${ }^{*}$

After the publication of our article [1], we noted that Figure five (Figure 1 here) was published with part of the figure missing. We now provide a corrected version of Figure five (Figure 5) and wish to apologize for any inconvenience our error may have caused.

\footnotetext{
* Correspondence: laura.fantuzzi@iss.it

${ }^{1}$ Department of Hematology, Oncology and Molecular Medicine, Istituto Superiore di Sanità, Rome, Italy

Full list of author information is available at the end of the article
} 
A

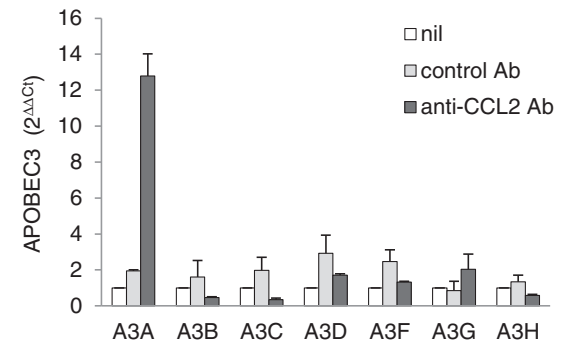

C

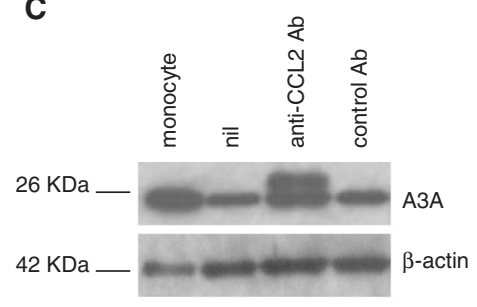

B

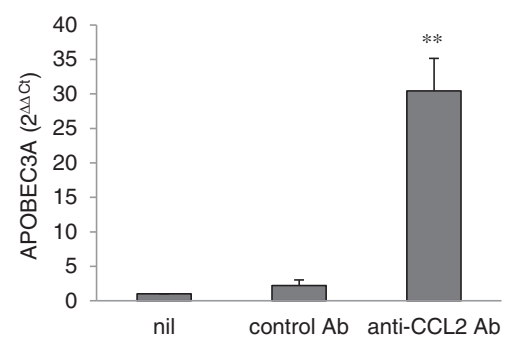

D

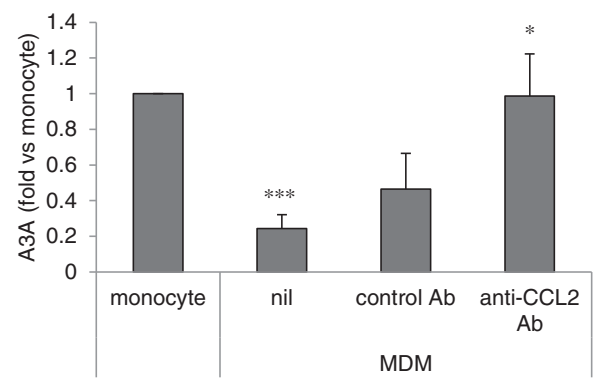

$\mathbf{F}$

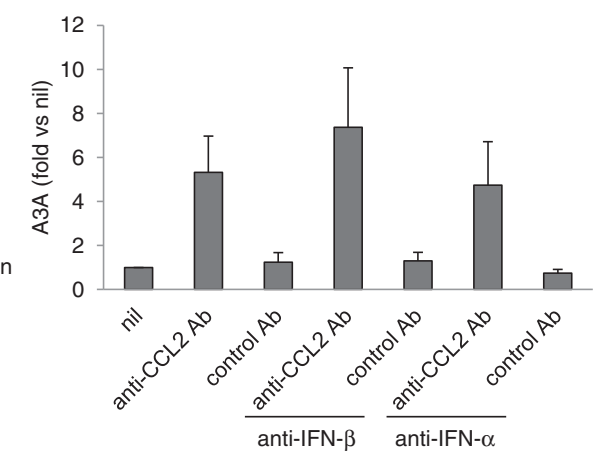

H

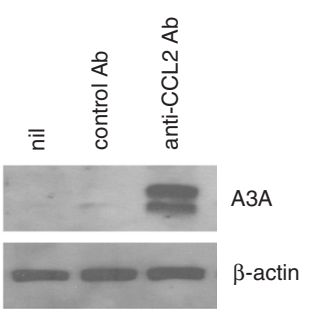

Figure 1

\section{Author details}

${ }^{1}$ Department of Hematology, Oncology and Molecular Medicine, Istituto Superiore di Sanità, Rome, Italy. ${ }^{2}$ Department of Therapeutic Research and Medicines Evaluation, Istituto Superiore di Sanità, Rome, Italy. ${ }^{3}$ National AIDS Center, Istituto Superiore di Sanità, Rome, Italy. ${ }^{4}$ Department of Molecular, Cell, and Developmental Biology, University of California Los Angeles, Los Angeles, California 90095, USA.

\section{Reference}

1. Sabbatucci M, Covino DA, Purificato C, Mallano A, Federico M, Lu J, et al. Endogenous CCL2 neutralization restricts HIV-1 replication in primary human macrophages by inhibiting viral DNA accumulation. Retrovirology. 2015;12:4.

Published online: 09 June 2015 